\title{
THE REAL SECTOR OF THE ECONOMY: FACTORS AND TRENDS IN MARCH 2015
}

\author{
O.Izryadnova
}

According to the preliminary data of the Ministry of Economic Development of the Russian Federation, in Q1 2015 GDP amounted to 97.8\% against the index of Q1 2014. A simultaneous shrinkage of consumer demand and investments in capital assets had a negative effect on the domestic market in 2015. In Q1 2015, the retail trade index and the index of investments in capital assets amounted to $93.3 \%$ and $94.0 \%$, respectively, as compared to the same period of the previous year. The situation in the economy is complicated by a $8.3 \%$ drop in real wages and salaries and a 1.4\% growth in the rate of unemployment as compared to Q1 2014.

According to the preliminary data of the Ministry of Economic Development of the Russian Federation, in Q1 2015 GDP decreased by $2.2 \%$ as compared to the same period of the previous year. In January-March 2015, the economic situation was determined by a simultaneous shrinkage of investment and consumer demand. In Q1 2015, investments in capital assets and the volume of jobs in building amounted to $94.0 \%$ and $95.3 \%$, respectively, as compared to the relevant indices of the previous year; it is to be noted that the extent of activities in the building and investment complex has been shrinking since H2 2013.

Low investment demand has determined weak dynamics of growth rates of the Russian economy in the past three years and reflected deep structural problems of the economy. From H2 2014, the situation was complicated by a decrease in funding of investment projects in a situation of general slowdown of the economy and high interest rates on loans. It is to be noted that investment demand is affected by such factors as uncertainties related to geopolitical tensions and sanctions, as well as a drop in confidence of private investors in stability of the Russian economy and low ratings of the investment climate. In addition to the above, problems related to inefficient distribution of inputs in the economy have aggravated even further. In a situation of a limited access to external financing, the issues related to efficient utilization of incomes of the economy for upgrading of the potential of growth and efficiency, including that from export of primary resources have become topical. According to the forecast of the Gaidar Institute, in 2015 investment demand will remain at the extremely low level, so, upgrading of the efficiency of utilization of production capacities $^{1}$ is to become the main factor of support of the economy. A decrease in the share of machines and equipment in the pattern of investments in capi-

1 The Model Calculations of Short-Term Forecasts of Social and Economic Indices of the Russian Federation. E-Journal: Scientific Bulletin of the Gaidar Institute.ru No.3( 85). P. 7.

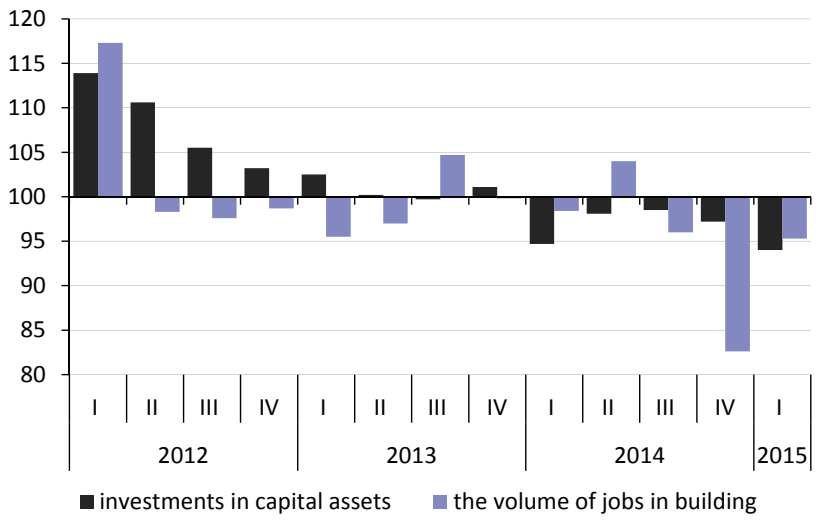

Source: The Rosstat.

Fig. 1. Dynamics of investments in capital assets and the volume of jobs in building in the 2012-2015 period,

as $\%$ of the respective quarter of the previous year

tal assets due to a drop in domestic production and import of capital goods, dramatic growth in the cost of imported equipment, appreciation of credit resources and nearly a three-fold reduction of the extent of direct foreign investments may inhibit modernization and introduction of innovation technologies which are important for upgrading of the potential for economic growth. It concerns, in particular, development of technologies of oil and gas production at deposits which are difficult to access.

Growth in loans-related costs, reduction of the profit and limitation of the access to international capital markets will inevitably result in revision of investment programs of 2015 and affect domestic private business sentiments. Proceeding from apprehension of the shift of risks towards slowdown of the economy, the Central Bank of the Russian Federation has lowered for the second time this year the key rate from $15.0 \%$ (02.02.2015) to $14.0 \%$ (16.03.2015).

Both dramatic depreciation of the ruble and the high rate of inflation have resulted in a sudden reduction of households' incomes and consumption. From January 2015, weakening of the dynamics of consu- 
mer demand - which was registered throughout 2014 - was characterized by a dramatic year on year reduction of the volume of the retail trade and paid services to households. In March 2015, the retail trade volume and the volume of paid services to households amounted to $91.3 \%$ and $98.0 \%$, respectively, against the relevant indices of the previous year. It is to be noted that in March 2015 a drop of $7.5 \%$ and $9.9 \%$ was registered in the volume of food market and non-food market, respectively, as compared to March 2014. If the dynamics of demand on food products was affected greatly by the level of the rate of inflation and dynamics of households' incomes, the shrinkage of the non-food market is partially related to households' accumulated reserves during speculative demand in November-December 2014.

If during the past seven years dynamic growth in households' incomes and consumption was underpinned by growth in wages and salaries in the public and private sectors of the economy, demand on workforce, labor efficiency, as well as pensions and social benefits, in 2015 slowdown of growth rates of economic growth and toughening of the policy of social expenditures may endanger stability of those trends. Though in the 2012-2014 period the indices of prosperity and the level of poverty remained at the same invariable level, in 2015 the risks to socially vulnerable groups of the population have increased greatly with advanced growth in prices on food as compared to the general rate of inflation; it is to be noted in particular that the poverty level may be raised for the first time since the 1999 crisis.

In March 2015, households' real income and real wages and salaries amounted to $98.2 \%$ and $90.7 \%$, respectively, while the actual size of accrued pensions, to $96.9 \%$ (the preliminary estimate) against the indices of March 2014. In March 2015, the consumer inflation amounted to $16.9 \%$ against March 2014 which situation was mainly justified by sudden growth in food market prices. In March 2015, the indices of food prices and non-food prices amounted to $111.8 \%$ (103.7\% a year before) and $106.8 \%$ (101.4\%), respectively, as compared to December 2014. It is to be noted that in February-March 2015 gradual slowdown of the rates of the monthly inflation was registered which situation is probably related both to easing of the effect of depreciation of the ruble and tough limitations on the part of consumer demand.

Shrinkage of domestic demand determined the dynamics of industrial output and market infrastructure. In March 2015 and Q1 2015 industrial output fell by $0.6 \%$ and $0.4 \%$, respectively, as compared to respective periods of the previous year. According to the data on Q1, positive dynamics of mining prevailed

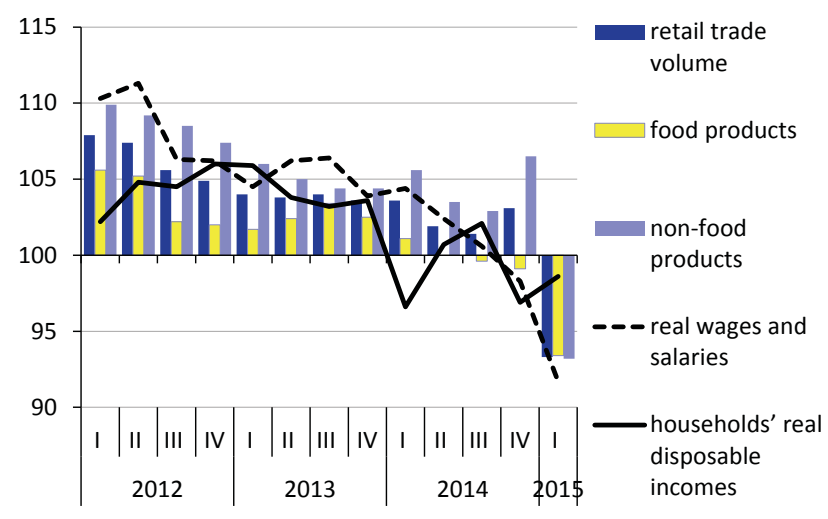

Source: The Rosstat.

Fig. 2. Indices of the retail trade volume and households' incomes in the 2012-2015 period, as $\%$ of the respective quarter of the previous year

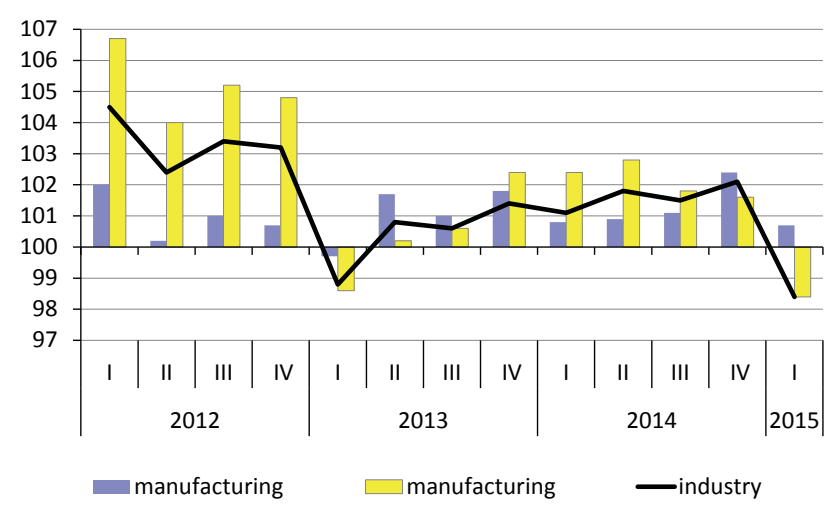

Source: The Rosstat.

Fig. 3. Industrial output indices by the type of economic activities in the 2012-2015 period, as $\%$ of the respective quarter of the previous year

with growing slump in manufacturing. In JanuaryMarch 2015 and March 2015, the volume of mining output rose by $0.7 \%$ and $0.4 \%$, respectively, against the respective periods of the previous year.

In March 2015, in manufacturing the output fell by 1.9\% as compared to March 2014. In March 2015, yearon-year positive dynamics was registered only in three types of economic activities: production of food products (102.3\%); production of charred coal and petrochemicals (100.9\%) and chemical production (111.4\%). In March 2015, a slump in engineering was in the range of $3 \%$ to $6.1 \%$ by different types of economic activities. In Q1 2015, the dynamics of output of transport vehicles and equipment was affected by a $19.6 \%$ decrease in the output of the automotive industry as compared to the same period of the previous year. It is to be noted that if in 2014 growth in output of vessels and flying and space vehicles demonstrated sustained positive dynamics, on the basis of the results of January-March 2015 the output fell by $10.6 \%$ as compared to the respective period of the previous year. 
On the basis of the results of Q1 2015, the total number of the unemployed increased by $2.6 \%$ as compared to the same period of the previous year. The above factor is of a particular concern in a situation of downward dynamics of households' incomes and wages. In 2015 the labor market responded to that by growth in the extent of incomplete employment. The above measure permits to preserve the personnel and maintain the standard of living of the population. The result of that policy is a reduction of employers' need declared to state employment agencies - in workers.

According to the methods of the ILO, in March 2015 the number of the unemployed increased by $2.1 \%$ against the previous month and amounted to $4.5 \mathrm{mil}-$ lion persons $(5.7 \%$ of the gainfully employed population); $1.0 \mathrm{~m}$ unemployed persons were registered with state employment agencies which value is $1.1 \%$ higher than in February 2015.

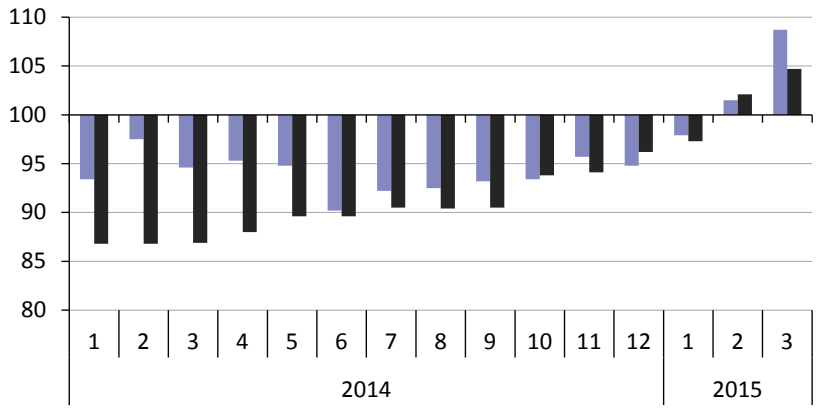

the total number of the unemployed

v the number of the officially registered unemployed

Source: The Rosstat.

Fig. 4. Dynamics of the total number of the unemployed and officially registered unemployed in the 2014-2015 period, as \% of the respective month of the previous year 